\title{
LUISA CARNÉS: A HISTÓRIA DE UMA ESCRITORA EXILADA
}

\author{
Ana Paula Cabrera ${ }^{1}$ \\ Luciana Ferrari Montemezzo ${ }^{2}$
}

Resumo: Os autores de exílio assumiam uma proposta quase missionária, revisando infinitamente os infortúnios do passado, mas sobretudo comunicando os sucessos de um passado recente, escrito durante o exílio. Entre esses escritores, destacamos uma em particular, Luisa Carnés (Madrid, 1905- México D.F, 1964). Neste artigo propomos apresentar parte da história dessa escritora, marcada pelo silenciamento imposto pela ditadura franquista (1939-1975), que atingiu com ainda mais contundência as escritoras exiladas. Além disso, também analisaremos o conto Montserrat, Heroína Catalana, escrito em 1936 e publicado na antologia De Barcelona a la Bretaña Francesa, em 2014, na Espanha. Com tal trabalho, acreditamos contribuir para resgatar um pouco a trajetória de uma escritora republicana à frente de seu tempo e até hoje silenciada.

Palavras-Chave: Histórias de exílio; Luisa Carnés; Reconstrução.

Abstract: The perpetrators of exile took on a quasi-missionary proposal, endlessly reviewing the misfortunes of the past, written during exile. Among these writers, we highlight one in particular, Luisa Carnés (Madrid, 1905- Mexico D.F., 1964). In this article, we propose to present part of the history of this writer, marked by the silence imposed by the Franco dictatorship (1939-1975), which hit even more exiled writers. In addition, we will also analyze the tale Montserrat, Heroina Catalana, written in 1936 and published in the anthology De Barcelona a la Bretaña Francesa, in 2014, in Spain. With such work, we believe contribute to a little rescue the trajectory of a Republican writer ahead of her time and still silenced.

Keywords: Stories of exile; Luisa Carnés; Reconstruction.

1 Doutoranda do Programa de Pós Graduação em Letras (PPGL) - UFSM. E-mail: paulacabreraes@gmail.com

2 Professora da Universidade Federal de Santa Maria. E-mail: lucesfm@gmail.com

Literatura e Autoritarismo, Santa Maria, n. 34: Imagens da Opressão, jan.-dez. 2019, p. 5-18. - ISSN 1679-849X 


\section{INTRODUÇÃO}

Luisa Carnés nasceu no bairro madrilenho de Las Musas em 1905 e cresceu em Chamberí, bairro popular da capital espanhola. Era a filha mais velha de uma família de origem humilde. Seu pai, Luiz Carnés Sanchez, era barbeiro e sua mãe, Rosario Caballero Aparicio, antes de se casar era costureira, depois ajudava a complementar a renda familiar com trabalhos esporádicos. Nesse período, tradicionalmente quando as mães trabalhavam, era a filha mais velha que se encarregava de todo trabalho doméstico. Nesse ambiente Carnés, segundo relembra seu filho Ramón Puyol (2006), teve muitas responsabilidades desde pequena: por exemplo, aos onze anos começou a trabalhar com sua tia Petra Caballero, em uma oficina de confecção de chapéus. Várias personagens femininas de seus artigos expressam essa ausência da infância.

Na Madrid do começo do século XX, a mão de obra infantil era muito comum. Quase sempre essas crianças eram empregadas clandestinamente. Existiam muitas restrições para o trabalho de mulheres e crianças, mesmo assim o salário feminino e das crianças significavam uma renda extra indispensável para sobrevivência das famílias. Os filhos varões ingressavam em fábricas ou nas minas, e as meninas com seus trabalhos domésticos ajudavam a compor a renda sem comprometer o trabalho dos homens.

A obrigação de trabalhar na infância complicava ainda mais o acesso da mulher de classe baixa aos estudos. Depois de trabalhar na pequena oficina de confecção de chapéus, Carnés trabalhou como atendente em uma confeitaria e logo foi para a Compañía Ibero-americana de Publicaciones (CIAP). Para uma mulher que só tinha a educação básica, as opções de um trabalho melhor eram muito reduzidas àquela época.

Durante muitos anos, Luisa Carnés mesclou o trabalho manual com a escrita, publicando seus primeiros contos em revistas e jornais. Antes da Guerra da Espanha ${ }^{3}$ (1936-1939) a narrativa carnesiana representava a mulher da classe trabalhadora, descrevendo as opções dessas mulheres na sociedade espanhola dos anos trinta. Incluída em um grupo feminino emergente, sua obra se localiza dentro de um período de importante transformação social.

Desde que Luisa se conscientizou do significado político que representava a Segunda República, assumiu com referência pessoal o compromisso com os ideais republicanos, que representavam um símbolo da democracia, e dos valores associados a ela. Além disso, assumia a defesa daqueles que considerava terem tido um comportamento exemplar em apoio à democracia republicana e à história do povo espanhol, submetido posteriormente à longa ditadura franquista (1939-1975).

Portanto, a trajetória desta escritora autodidata, filiada ao Partido Comunista da Espanha nos anos de 1930, exilada no México depois da Guerra da Espanha, descreve a luta de milhões de mulheres silenciadas pelo exílio e esquecidas por sua pátria. Contar essa história é resgatar e preservar a memória e o testemunho de um momento histórico daqueles que

3 Utilizaremos, ao longo deste trabalho, a expressão Guerra da Espanha, em lugar de Guerra Civil Espanhola. Embora a segunda seja muito mais aceita academicamente do que a primeira, consideramos que o referido conflito teve importante participação do exército espanhol, além da intervenção direta dos governos da Itália, da Alemanha e da URSS (Jorge: 2016) - a ponto de ter como principal consequência uma ditadura comandada por um general. Assim sendo, avaliamos ser inadequado utilizar uma expressão que, à primeira vista, exclui tal participação. 
foram obrigados a deixar a Espanha, sobrevivendo à desesperança e angústia de uma das maiores tragédias da história do país, que transpassou gerações.

Para Luisa, a chegada da República (1931) significou, por um lado, a composição de um novo espaço político e social e por outro, a urgência de uma nova identidade feminina. Para tentar situar a obra de Luisa Carnés, é indispensável, em primeiro lugar, explicar um pouco da sua trajetória, sem a qual seria quase impossível compreender sua produção literária.

\section{A LITERATURA DE LUISA CARNÉS}

O trabalho de Luisa Carnés se enquadra na tradição da novela social e a aproxima de suas contemporâneas que perseguiam os mesmos objetivos. Se alguma palavra pudesse definir Luisa Carnés como escritora essa palavra, para nós, seria: segregação. A escritora silenciada por mais de cinquenta anos pela ditadura franquista é de suma importância para resgatar a história e a historiografia de todo um período desse delicado tema que é o exilio espanhol. Em suas obras existe um distanciamento, um dos pontos mais relevantes que podemos notar, desde o seu primeiro romance, Peregrinos de Calvario (1928), no qual observamos um movimento contínuo que determina a existência como um encontrar-se fora de lugar.

Seus romances silenciados têm sido editados e reeditados desde 2002, devido ao cuidadoso trabalho de pesquisa do historiador Antonio Plaza, como parte da história do exílio espanhol. Entre eles temos: Natacha (1930); Tearooms, mujeres obreras (1934), De Barcelona a la Bretaña Francesa (1939); La hora del odio-inédito (1944); Rosalía de Castro, raiz apasionada de Galicia (1945); Elegía de los siete puñales de la madre-obra poética-inédita (1952); Juan Caballero (1956) e o inédito El eslabón perdido, editado por Antonio Plaza em (2002). Além destes romances, a autora também deixou obras de teatro, recentemente encontradas no México tais como: Cumpleaños (1966), Los vendedores del miedo (1966), entre outros que continuam inéditos ou ainda não foram localizados.

Carnés é uma trabalhadora que toma a palavra e se converte em um ser político, preocupado com os marginalizados e principalmente com as mulheres, converte-se em um ser que talvez não tenha encontrado o seu lugar no exílio, mas que fez dele um instrumento para recordar as terras longínquas da Espanha.

Não temos como precisar historicamente como a Guerra da Espanha fragmentou a trajetória de várias gerações perdidas para sempre. Muitas pessoas deixaram para trás qualquer possibilidade de realização plena de em suas vidas. A luta diária, repleta de incertezas do exílio, ajudava os exilados a reconstruir a memória, e a história do país de origem por meio da escrita. A história das escritoras espanholas, especificamente aquelas exiladas pela ditadura franquista, é marcada por uma trajetória de resgates. Por longo tempo, muitas delas ficaram à margem da crítica e da historiografia literária. Apenas recentemente vêm sendo objeto de investigação.

Luisa Carnés, assim como muitos escritores espanhóis exilados, ficou esquecida por mais de cinquenta anos. Mesmo após tantos anos e tantas publicações, suas obras ainda são 
desconhecidas da maior parte do público leitor espanhol. Atualmente, o país faz uma espécie de esforço revisionista, para dar a conhecer e reeditar a literatura de autores exilados, embora se saiba que essa literatura, em grande parte, foi elaborada fora da Espanha. No caso específico de Carnés, o exílio aconteceu no México, país que acolheu grande número de espanhóis e que, portanto, recebeu forte influência da Espanha em seu cenário cultural.

\section{TEMPOS DE REPÚBLICA: O CONTEXTO POLÍTICO-CULTURAL DA ESPANHA NOS ANOS 1930}

A data de 01 de outubro de 1931 significou uma transformação para a vida política espanhola: a partir daquele dia, estava permitido o voto feminino em todo o país. Tal aprovação se deu graças à determinada luta empreendida pela deputada Clara Campoamor (1888-1972), do Partido Radical. Essa data marcaria não apenas uma importante modificação no sistema político, mas sobretudo na vida das mulheres espanholas. Plaza (1992, p. 28) relata que Luisa Carnés recordava a data com otimismo: “[...] Fíjate bien, estás viendo nacer una página en la historia de España". De fato, o poder do voto, agora outorgado à toda a população espanhola, teve consequências fundamentais para o que viria ser o país daquele momento em diante. Nas eleições municipais convocadas pela monarquia, em 14 de abril de 1933, a República ganhou a maioria dos votos da população. A contribuição das mulheres naquela ocasião foi primordial. O rei Alfonso XIII, por sua vez, acatou o resultado das urnas e retirou-se, sem oferecer resistência ao novo regime. "A Espanha dormiu monárquica e acordou republicana" é uma frase que, até os dias de hoje, costuma ser ouvida nas ruas da Espanha, referindo-se à paz com que a transição se realizou naquele momento.

Durante os primeiros meses da República, a participação social das mulheres era bem aceita. Na imprensa, surgiram vários artigos que ressaltavam o "tema da mulher" e o novo papel feminino. O número de publicações, sobretudo nos anos de 1931 a 1933 em jornais como Renovación, El Socialista, Mundo Feminino defenderam a independência econômica da mulher, desconsiderando seu estado civil. Esse foi um importante passo para que as mulheres conseguissem a cidadania plena. Por outro lado, as publicações conservadoras e católicas como El Debate, El Eco del Pueblo y Razón y Fe, empenhavam-se em manter as mulheres no âmbito doméstico.

Posteriormente, a categoria feminina da República, composta por mulheres que foram para o front, converteu-se em um símbolo político da realidade social. Além de significar uma promessa de renovação, também serviu de ferramenta crítica para os opositores do governo, o "antifeminismo" e o "antirrepublicanismo". A República foi desaprovada pelos setores mais tradicionais devido, entre outras coisas, à abertura política dada à mulher. Nesse aspecto, e chegou a ser questionada sobre sua "virilidade" pelo setor mais conservador, que ainda via a mulher moderna e o feminismo como um perigo ao equilíbrio social.

Luisa Carnés recordava em um dos seus artigos publicados no exílio mexicano a mulher moderna da República: "Si algo había cambiado en Madrid de antes de la guerra, era el atuendo feminino, en los peinados" (1952, p. 3). As mudanças radicais que ocorreram como a lei do casamento, do divórcio, do trabalho e do direito ao voto, eram bem mais políticas: 
uma tentativa de copiar um sistema mais liberal de outros países, mas não significaram uma verdadeira revolução cultural em prol da mulher. Ainda assim, a República, apesar de suas falhas, representou um passo adiante na situação das mulheres.

Em vários artigos publicados durante a guerra, Carnés relata as principais medidas republicanas para a educação feminina. Entre elas, figurava a diminuição do analfabetismo como ponto crucial, já que as mulheres tinham que trabalhar antes mesmo de aprender a ler e a escrever.

\section{MONTSERRAT, HEROÍNA CATALANA}

A partir de suas memórias, Luisa Carnés escreve De Barcelona a la Bretaña Francesa, em 1936. Fiel ao seu compromisso, marca a constância dos acontecimentos vividos, utilizando-se da escrita como forma de garantir que os fatos históricos silenciados sejam conhecidos e valorizados pelo leitor. Os contos que compõem o livro apresentam o testemunho pessoal da autora.

A primeira parte do exílio acontece como uma peregrinação: relatando a necessidade que muitos republicanos tiveram de fugir a pé da Espanha, para não serem capturados pelos nacionalistas, que estavam ganhando a guerra. O primeiro relato ocorre pouco antes de terminar a guerra, em uma espécie de restaurante de Barcelona, e o último descreve a situação das mulheres refugiadas no Château Aérium Marin de Bréceáu, no momento que Luisa está prestes a partir para o exílio.

No conto Montserrat, Heroína Catalana, pertencente a esta obra, Carnés narra a história da jovem catalã que trabalhava antes da guerra em uma fábrica têxtil de Barcelona, evidenciando as dificuldades por que passaram as jovens mulheres espanholas. Se, por um lado, a República trouxera ventos de liberdade, por outro, diminuíra o poder de compra da elite - já maculado pela quebra da Bolsa de Nova Iorque em 1929. Com isso, começou uma recessão econômica e, a partir dela, houve uma considerável diminuição dos postos de trabalho. Diante deste contexto tão paradoxal, era preciso aferrar-se àquilo que garantisse o sustento e a sobrevivência:

Montserrat es una de tantas heroínas de la independencia de España. Esta muchacha catalana trabajaba antes de la guerra en una fábrica textil de Barcelona. Vivía en el barrio obrero del Clot, no lejos de la Estación del Norte. Abrió los ojos a un panorama de chimeneas y cables de alta tensión. La acunaron largos silbidos de locomotoras y sirenas de paz, que marcaban su trabajo y el reposo de los trabajadores. También le llegaba la canción marinera de los barcos que atracaban al puerto. (CARNÉS, 2014, p.77).

Se, antes da guerra, já era difícil manter-se no mercado de trabalho, depois de sua eclosão, isso se tornou ainda mais difícil. Apesar disso, a protagonista segue determinada, lutando valentemente por seu trabalho, independência e liberdade. 
Al estallar la guerra, millares de obreras del textil quedaron paradas. Montserrat fue una más de las mujeres que se endurecieron en largas jornadas de trabajo agotador. A las pocas semanas de haber comenzado a trabajar, producía mayor número de piezas que cualquier obrera de la misma fábrica. Tenía diecinueve años. (CARNÉS, 2014, p.77).

A autora expõe a dura realidade da mulher em tempos de guerra como um abnegado símbolo da Espanha, que foi subjugada, segregada e condenada à própria sorte. Montserrat, a protagonista do conto, torna-se, então, uma espécie de símbolo da jovem Espanha republicana, que luta por manter suas conquistas ainda que, para tanto, precise verter seu próprio sangue em prol da liberdade tão duramente conquistada.

Era morena y delgada. Sus manos comenzaban a agrietarse y a endurecerse por las duras tareas. La falta de alimentación afinaba sus rasgos, pero los ojos de Montserrat parecían más brillantes y vivos que antes. La fiebre constante de producir más y más la obsesionaba. Llegó a ser la primera obrera de la fábrica. Pasó a ocupar puestos de gran responsabilidad. Fue estímulo de las demás obreras, incluso de las viejas noieras4, procedentes también del textil. Junto a su máquina, adelgazada por las privaciones y por las duras jornadas de trabajo intensivo, pero con la mirada inflamada en ardores de creación, de superación, Montserrat era el símbolo abnegado de la mujer de España, que todo lo ha ofrecido a la causa de la libertad de su pueblo invadido. Ella dio su brazo derecho. La máquina lo desgajó del cuerpo fino y gracioso de Montserrat, en un atardecer de primavera. La polea grande lo sacudió en el aire viciado por el plomo y lo aplastó contra una de las oscuras paredes de la nave. Gritos de horror y acentos compasivos mecieron el desmayo pálido de Montserrat. Tardó muchos meses en curar (CARNÉS, 2014, p.78).

A perda do braço, nesse sentido, além de uma denúncia da cruel realidade a que estavam submetidas as jovens trabalhadoras, converte-se em metáfora da sangrenta guerra que ceifou a vida de aproximadamente 540.000 espanhóis. É preciso lembrar que, à época, a população da Espanha estava estimada em pouco mais de 24.000.000 habitantes (ZOIDO NARANJO \& ARROYO PÉREZ, 2003, p. 22). Tendo em vista estes dados, é possível afirmar que mais de vinte por cento da população do país morreu na Guerra ou em consequência dela: "[...] En esos dígitos se contabilizan no solo los caídos en combate o en las represalias, sino también quienes perecieron por las malas condiciones de vida, la mala salud o la desnutrición; las víctimas en diferido del horror fratricida" (ABAD LIÑÁN, 2019, s.p.). Calcula-se que houve em torno de 450.000 exilados (RAMÍREZ, 2019, s.p.).

O relato carnesiano, portanto, vai ao encontro da realidade, para recriá-la literariamente. Assim, dá especial atenção à possibilidade de denúncia que a ficção permite em épocas de censura. No mesmo conto, a autora também se refere às pequenas meninas, que

4 Refere-se às meninas que estiveram empregadas como trabalhadoras infantis na indústria têxtil. (PLAZA, 2014, p.78-

Tradução nossa). 
foram empregadas como trabalhadoras infantis na indústria têxtil e em várias outras instaladas pelo país. Trata-se de uma mescla de crítica e lembrança de sua infância, uma vez que, como dissemos ao princípio, a própria autora trabalhou na indústria de chapéus com apenas onze anos.

Após o trágico acidente, Montserrat converte-se na heroína de Barcelona. Carnés declara que por algum tempo Montserrat era considerada o orgulho da Cataluña e de toda Espanha. A jovem era o orgulho de sua pátria, assim como muitos homens que perdiam suas vidas diariamente pela Espanha. Juntamente à denúncia da situação em que se encontram as mulheres nas cidades, Carnés também destaca o abandono dos soldados mutilados, que agora vivem em um abrigo em condições precárias, às mães que precisam deixar seus filhos para trás em meio aos bombardeios que não cessam e à luta das mulheres que respondem à convocação do governo:

[...] Entre los objetos, cuerpos humanos se amontonan; cuerpos de aspecto desolador, evacuados de los pueblos inmediatos de Barcelona, que cargaron con los modestos enseres que pudieron salvar; hombres mutilados y enfermos; ancianos de ojos apagados" (CARNÉS, 2014, p.79).

Depois do acidente, Montserrat passa a trabalhar no sindicato e continua acreditando que somente com esforço de todos poderão vencer a guerra. Em meio à dor, notamos que a esperança de conseguir um governo democrático se mantém presente. As tropas invasoras preparam o ataque final, a Espanha vive momentos críticos da ocupação das tropas nacionalistas:

[...] Solo el esfuerzo de todos hará posible en triunfo de la República, contra el enemigo mil veces superior. Creo en el heroísmo de nuestro pueblo, porque lo he visto actuar en los frentes y en las fábricas. Somos hoy ejemplo y orgullo de todos los pueblos del mundo. Tanta sangre vertida, tanto sacrificio, no pueden perderse. [...] Montserrat alarga el brazo hacia las Ramblas y me muestra una espesa columna de humo negro: - Acertaron en el puerto, los canallas (CARNÉS, 2014, p. 81).

A intervenção das mulheres na guerra variou de acordo com a situação de cada uma no início do conflito. Nas primeiras semanas, algumas delas se uniram aos grupos armados no campo de batalha, respondendo à convocação dos republicanos. Pouco depois, colocou-se em prática um projeto que obrigava que elas saíssem das frentes de batalha e fossem para retaguarda - que se converteu no principal espaço de ação feminina. Aquelas que se integraram à luta armada foram motivadas pela consciência social, vista como "[...] a continuación de su previa dedicación a los movimentos sindicales" (OLMEDO, 2014, p.172). Devido ao apoio à causa antifascista, muitas mulheres foram para a cadeia ou para o exílio. Assim, De Barcelona a la Bretaña Francesa é uma obra que representa um documento introdutório sobre a experiência do exílio republicano. 


\section{TEMPOS DE EXÍLIO: VIDA E RESISTÊNCIA NO MÉXICO}

Ao terminar a Guerra da Espanha, vários intelectuais se viram obrigados a deixar o país. Muitos deles chegaram ao México graças a ajuda de Lázaro Cárdenas (presidente do México entre 1934 a 1940). O número exato da chegada desses espanhóis ao México ainda é desconhecido, mas os registros apontam para uma maioria masculina. Isto se deve ao fato de que as mulheres que permaneceram nos partidos políticos foram poucas. A maior parte das mulheres que chegaram ao México pertencia ao núcleo familiar exilado e não tinha formação profissional.

Luisa Carnés fazia parte de um grupo minoritário, formado por intelectuais modernas. Essa categoria feminina do exílio, de acordo com Plaza (2002), constitui uma das particularidades do exílio republicano de 1939, uma vez que o exílio havia sido até então, uma experiência predominantemente masculina.

Esse pequeno número de espanhóis formou no México, uma comunidade de exilados que tinham redes de colaboração e apoio, conservando certo grau de isolamento. A pequena sociedade se aglomerava ao redor das fazendas de café, mantendo a identidade do seu povo, como um lugar de memória. Fundaram escolas, centros de reuniões, celebração de 14 de abril com hino e bandeira republicana, tudo com o forte propósito de retornar à pátria.

Tal sentido de comunidade idealizava um nacionalismo de exílio artificial, que se distorcia com o passar do tempo, à medida que surgiam as imagens de recordações. Por meio destes núcleos, construía-se uma falsa realidade, talvez ainda fruto de um processo de negação da saída forçada do país de origem, gerando laços que certamente repercutiram na concepção da obra de exílio. Dessa maneira, a literatura no exílio se constituía no âmbito das preocupações comuns relacionadas ao lugar que se deixou: a Espanha.

Ao que tudo indica, o deslocamento do autor de exílio faz com que ele se sinta fora do seu lugar, e ele sempre se questiona: para quem escrevo? Escrevo para aqueles que se encontram na fronteira, entre duas pátrias. Nesse sentido, sentir-se fora de contexto, faz com que o escritor de exílio questione sua capacidade de influência. Tal preocupação parece ser demonstrada devido à impossibilidade de chegar ao público para quem ele escrevia habitualmente.

Com o passar dos anos, esse discurso perde o sentido, a expectativa de retornar à pátria passa a ser o último fio de esperança. Adaptar-se a essa nova realidade é imprescindível, já não há mais o antigo processo de negação da saída do país natal. Os escritores notam que devem estabelecer laços com a nova realidade que os cerca, e é no cotidiano que a maioria dos intelectuais exilados passa a ver uma luz.

Inicialmente os exilados aspiravam uma adaptação provisória, que lhes permitiria sobreviver sem deixar de lado o interesse político da Espanha. A maior parte da narrativa de Luisa Carnés expressa essas inquietudes. Com o passar dos anos, os temas se ampliam e diversificam: as dificuldades do exílio, a esperança de retornar - temas antes excluídos-, passam a constituir a realidade e se transformam em argumento de escrita. A separação da sua terra natal, a guerra e a sua origem têm grande repercussão na obra carnesiana, que nos primeiros anos de exílio começa a analisar seu papel na guerra por meio dos textos publicados nos jornais mexicanos, nos quais relata sua experiência. 
Para os exilados republicanos, os pactos de setembro de 1953 representaram a garantia da sobrevivência do franquismo, o que consequentemente implicou no fim da esperança do retorno da democracia na Espanha. Luisa Carnés escreve então em Los bancos del Prado (1953), outro de seus textos inéditos, uma resposta aos pactos do governo franquista com os Estados Unidos e Espanha, que levaram a instalações de bases militares na Espanha. Tal medida foi duramente criticada pelos intelectuais exilados no México, mas resultou quase irrelevante na Espanha.

Ao mesmo tempo, Luisa Carnés tem sua literatura reconhecida no México e mantém o firme propósito de incentivar mudanças políticas e sociais com a sua escrita. Por meio dela, tenta modificar a situação da Espanha, e passa a compreender sua situação de exilada. A autora afasta-se provisoriamente do comunismo e da perspectiva de gênero, mas sua escrita é sempre utilizada como ferramenta principal de ação. Sua obra encontra-se embasada em duas áreas: a política - que Luisa desenvolve em seu trabalho jornalístico, refletida em seu único romance publicado no México, Juan Caballero (1956), e a pessoal, formada por artigos e contos registrados em publicações periódicas e pela biografia Rosalía de Castro (1945). Essas duas últimas obras são as mais extensas que a autora publicou em vida.

Parece ser comum ao escritor exilado estabelecer um comparativo do lugar que se deixou com o lugar em que vive. Frequentemente recorrem ao presente que deixaram no passado e reconstroem, por meio da memória, a paisagem que observam no presente, estabelecendo comparações com lugares que possam parecer comuns entre as duas pátrias (México e Espanha). Carnés escreve vários artigos com essa temática, mesmo sendo o México e a Espanha tão diferentes, a autora estabelece uma relação entre os dois países. Para ela, um elemento que constitui uma das principais similitudes entre os dois países é o mar, que Carnés descreve em seu romance El eslabón perdido (2002), por meio do olhar de seu personagem César Alcántara, um professor de literatura cuja carreira havia terminado com a guerra.

Cabe ressaltar que os textos de Carnés abarcam dois conjuntos que evidenciam o ideal exilado: um que expressa parte de uma realidade desconhecida; e outro que denuncia o que acontece em seu entorno. Olmedo esclarece que: “(...) Los intelectuales exiliados se consideran a sí mismos parte de la cultura en la que ya no sólo participan, sino también escriben y la mayoría habla de México" (2013, p. 214). Dessa maneira, a escritora passa a escrever romances e contos que expõem as realidades que a envolvem.

Com o tempo, a cidade do México passa a representar uma contradição da modernidade, a escritora observa que essa divisão ocorre de duas maneiras: uma que compreende novos modos de vida e costumes menos tradicionais; e outra, que inclui o lugar onde existe a corrupção, a pobreza e a exploração. Após muitos anos, a escritora consegue entender sua nova realidade, não mais com a visão de turista, e sim a partir de sua própria experiência de exilada.

Parece que a obra carnesiana reflete parte de uma memória que se encontra partida pela circunstância histórica, o tema do regresso mostra essa divergência entre um passado idealizado e um presente que não é vivido como tal. Com o decorrer dos anos, o tema da revolução e da narração indigenista no México se revela como valiosa fonte de inspiração.

Os narradores exilados notam que as linhas de mestiçagem proporcionam a verdadeira identidade mexicana. Juan Rejano escreve em 1945, La esfinge mestiza, do mesmo modo 
que Luisa Carnés inclui a visão da mulher indígena como força geradora. Um exemplo desta vertente literária nos é apresentado anos depois, no conto: La prietita quiere una piel blanca (1951) publicado em 2018, no livro Donde Brotó el Laurel-Cuentos completos II, por Antonio Plaza. Neste livro de contos inéditos, fruto do trabalho incansável de Antonio Plaza, há narrações breves que a escritora compôs desde que iniciou sua carreira literária nos longínquos anos vinte do século passado.

Sabemos que refletir acerca das políticas institucionais, sobre a memória do passado antifranquista e sua cultura foi por muito tempo a principal pauta do exílio e da cultura contra o franquismo. Sobre isso, esclarece Muñoz Soro (2010, p.33):

[...] el recuerdo de la cultura antifranquista ha sido sobre todo el recuerdo de los intelectuales que evolucionaron desde el franquismo, o de los liberales que volvieron a su ser, puente con las nuevas generaciones que protagonizaron la democracia”.

A história dos intelectuais exilados parece se configurar como um subconjunto de uma história - distante do idealismo puro, estoicamente enraizada na análise dos contextos sociopolíticos onde esses intelectuais vivem. Uma cultura que de certa forma outorgou uma parte fictícia a um tipo de patrimônio nacional sobre o qual parece ter se estabelecido a democracia.

O povo espanhol sentiu na pele a tirania, Franco obteve apoio econômico e assessoramento da Alemanha nazista e da Itália fascista, países que aproveitaram a Guerra da Espanha para provar armas e metodologias bélicas, entre outras coisas. Massacraram cidades como Guernica - que sofreu as consequências do bombardeio e da violência massiva contra a população civil. Os que conseguiram escapar da violência física padeceram sob as leis do silenciamento.

Escritores, poetas e intelectuais foram vítimas preferenciais do estado fascista. García Lorca foi assassinado no primeiro mês do conflito, Miguel de Unamuno e Antonio Machado morreram de tristeza no final da guerra. Para muitos outros restaram os campos de concentração e o exílio. Luisa Carnés, Margarita Nelken, Isabel Oyarzábal, Juan Rejano, Max Aub, Rafael Alberti, Maria Teresa León e Luis Cernuda, entre outros, foram vozes que ecoaram de além-mar. De todos eles, apenas o casal Alberti-León regressou à Espanha. Os demais, morreram no exílio.

\section{CONSIDERAÇÕES FINAIS}

A história da literatura de exílio é uma construção de sentidos criada a partir de manifestações discursivas heterogêneas. Partindo de uma reavaliação de critérios, notamos que os anos de exílio representaram uma perda gradual de identidade. Tanto a análise da configuração da história literária como do cânone experimenta essa perda. O século XX é em parte o embrião do que somos hoje e, em parte, testemunho de um mundo alheio.

Mulheres que, como Luisa Carnés eram vistas como radicais na política, não só escre- 
veram fora da ordem estabelecida - porque escreveram desde uma perspectiva de esquerda, acerca de temas como política - que eram temas nos quais as mulheres eram consideradas "ignorantes". A personalidade de Luisa Carnés como escritora se constrói por meio da liberdade, da esperança, de sua colaboração em grupos de mulheres e, também, de publicações com intuito de captar afiliadas.

Os escritores espanhóis exilados da geração de 1939 mantiveram seus olhos na Espanha. Sua missão era responder para a Espanha, expondo sua visão dos episódios históricos como a guerra, a República, o exílio. Empregaram a literatura e os meios de escrita para realizar uma literatura nacional engendrada no exílio. Como afirma Olmedo (2013), valorizar o lugar do exílio intelectual espanhol na literatura mexicana tem um duplo propósito: discutir a institucionalização historiográfica e pedagógica da literatura, além de hierarquizar o papel da historiografia na formação do cânone, uma vez que o exílio coloca em crise preceitos clássicos apoiados na territorialidade nacional.

Carnés vale-se do artigo jornalístico para despertar a consciência social e encontra nos breves textos semanais o melhor meio de expressão - o jornal era um veículo de ampla circulação, tornando-se a melhor maneira de informar o público desejado. Os temas de seus artigos demonstram seu ideário de compromisso no exílio, sempre vinculado à situação da classe operária, da mulher e da Espanha. Por meio deste trabalho, Carnés produziu uma literatura conectada com a vida, concebida como uma ferramenta de ação.

Ao observarmos a obra de Carnés na Espanha e no México notamos que inicialmente em seus contos sobre a Espanha, Luisa desenvolve argumentos ambientados em lugares indeterminados ou imaginários, que ela deixou de retratar quando seu olhar mais crítico se fixou no entorno urbano que ela conhecia tão bem. Cenas do cotidiano, crianças e adultos trabalhando em condições precárias, a miséria e o abandono, como observamos na análise do conto Montserrat, Heroína Catalana (1936).

No México o olhar da escritora muda de acordo com seu entorno, a princípio ainda muito conectada aos acontecimentos de sua terra natal, recria os horrores da Guerra da Espanha, denuncia as condições desumanas das mulheres presas e de seus filhos, exalta a solidariedade e a luta antifranquista sem abandonar as preocupações sociais que guiam sua obra. Contudo, não inclui obrigatoriamente em sua obra- ao tratar do tema da Espanha, as teses que sua militância política impunha.

Carnés atua no México do mesmo modo que na Espanha - com um olhar atento ao seu entorno. Após alguns anos na condição de exilada, sua produção literária passa por um segundo momento: a autora deixa de lado a temática da Espanha, e passa a escrever contos ambientados no país em que se encontra. Inicialmente seus contos revelam temas como: a força da natureza, das lendas e costumes ancestrais, o dia a dia dos lugares, do comércio da cidade, trazendo à tona a história interna de uma parte importante da atividade econômica do México - o turismo. Depois passa a denunciar as injustiças e desigualdades sociais, bem como a complexa convivência que observou entre a população local e os descendentes dos europeus exilados. A escritora não fechou os olhos ao generoso país de acolhida, solidário com os exilados da geração de 1939, cuja nacionalidade Luisa adotou em 1941.

A recuperação da obra literária dessa escritora, injustamente esquecida e/ou silenciada pelo franquismo é de importante valia para uma proposta de revisão do cânone da Literatu- 
ra Espanhola. Entender o passado recente da Espanha, conhecer seus protagonistas, tentar compreender como funcionava aquela sociedade, é imperativo para os estudos de Literatura Espanhola. Recuperar anos de história perdida, resgatando a memória daqueles que foram forçados a fugir por defender seus ideais, perdendo sua liberdade, sua pátria e suas vidas significa rechaçar o esquecimento, reescrever a história e preencher lacunas.

\section{REFERÊNCIAS}

ABAD LIÑÁN, José. ¿Cuántas víctimas se cobró la guerra civil?. Disponível em:<https:// elpais.com/politica/2019/02/11/sepa_usted/1549896518_673788.html>. Acesso em: 01.nov.2019.

ARROYO PÉREZ, Andrés; ZOIDO NARANJO, Florencio (orgs.). Tendencias demográficas durante el siglo XX en España. Madrid: Instituto Nacional de Estadística, 2003.

CARNÉS, Luisa. La Libertad. Espasa-Calpe: Madrid, 1928. . Peregrinos de calvario. Madrid: CIAP, 1928.

SERNA, Justo e PONS, Anaclet. La cultura en España: Ensayo para un diagnostico. Madrid: Edicusa, 1971.

MARTÍNEZ CAPEL, Rosa M. De protagonistas a represaliadas. Cuadernos de Historia Contemporánea: Madrid, 2007.

MUÑOZ SORO, Javier. De los intelectuales y su pasado: usos públicos de la cultura antifranquista. Fundación Ortega y Gasset, 2010.

OLMEDO, Iliana. El lugar de la narrativa del exilio republicano en la historiografia literaria mexicana- La narrativa del exilio Republicano. México: Revista Secuencia, n. 85, janeiro-abril 2013, pp.111-137.

. Itinerarios de exilio. Sevillha: Editorial Renascimento, 2014.

ORTEGA. J.A. El País. Las muertes por culpa de la guerra y la posguerra. Disponível em: <https://elpais.com/politica/2019/02/11/sepa_usted/1549896518_673788.html> Acesso em: 06.nov.2019.

PIÑA ROSALES, Gerardo. Narrativa breve de Manuel Andújar. Biblioteca Virtual, 2003.

PLAZA PLAZA, Antonio. El eslabón perdido. Sevilla: Renacimiento, 2002. 
Luisa Carnés, una escritora olvidada. Madrid: Cuadernos Republicanos, 12 de octubre de 1992.

. De Barcelona a la Bretaña francesa. Renacimiento: Sevilla, 2014.

. Tea Rooms: Mujeres obreras. Galícia: Hoja de la Lata editorial, 2016.

SELIGMANN-SILVA, Márcio. Globalização, tradução e memória. In: Cadernos de Tradução: Florianópolis, EDUFSC/Núcleo de Tradução, vol. 04, 1996, p.151-166.

- Narrar o trauma: A questão dos Testemunhos de catástrofes históricas.

PSIC. CLIN, Rio de Janeiro, vol.20, n.1,2008, p. 65-82.

. Reflexões sobre a memória, a história e o esquecimento. M. (org.).

História, Memória, Literatura. O testemunho na era das catástrofes. Campinas: Editora da UNICAMP,2007, pp. 59-89. 
